Gut, 1985, 26, 861-864

Case report

\title{
Development of impaired splenic function in intestinal lymphangiectasia
}

\author{
P N FOSTER, A W BULlen, D A F ROBERTSON, D M CHALMERS, \\ AND M S LOSOWSKY \\ From the Department of Medicine, St James's University Hospital, Leeds
}

SUMMARY We describe a patient with intestinal lymphangiectasia who developed hyposplenism and speculate that it resulted from chronic loss of lymphocytes into the gut.

Splenic atrophy has been long recognised in association with coeliac disease ${ }^{1}$ and, more recently, impaired splenic function has been described in patients with ulcerative colitis and Crohn's disease. ${ }^{2}$ The aetiology of this hyposplenism is unknown, but by analogy with animal models it has been suggested that it results from lymphocyte depletion due to chronic loss into the gut. ${ }^{3}$

Intestinal lymphangiectasia is a disease characterised by dilated lymphatics, protein-losing enteropathy, hypoalbuminaemia and oedema, and patients with this disease lose albumin, immunoglobulins, and lymphocytes into the bowel. If the development of splenic atrophy results from prolonged lymphocyte depletion, it is likely that patients with intestinal lymphangiectasia will develop abnormalities of splenic function over a period of time, although, to our knowledge, this has not been studied.

Since 1976, various tests of splenic function have been applied to one of our patients with intestinal lymphangiectasia and the results are reported below. During this time, however, the patient also developed other clinical problems.

\section{Case report}

A 40 year-old man presented in 1975 with a past history of vagotomy and pyloroplasty for a duodenal ulcer. He now complained of epigastric discomfort, diarrhoea, and ankle swelling. Examination confirmed pitting oedema of the ankles but there were

Address for correspondence: Dr P N Foster, Dept of Medicine, St James's Hospital, Leeds LS9 7TF.

Received for publication 21 September 1984 no other abnormalities apart from the laparotomy scar. Investigation revealed a low serum albumin of $25 \mathrm{~g} / \mathrm{l}$. There was no proteinuria but ${ }^{131}$ I polyvinylpyrrolidone excretion in the stool was increased at $6 \%$ (Normal $<1 \%$ ). Serum IgG and IgM were reduced (3.87 and $0.34 \mathrm{~g} / 1$ respectively), serum $\operatorname{IgA}$ was normal. The absolute lymphocyte count was $1846 / \mathrm{mm}^{3}$ of peripheral blood. Dissecting microscopic and histological examination of duodenal and jejunal biopsies showed that approximately $2 \%$ of villi were distended with lipoid material. A small bowel enema revealed oedematous mucosal folds and in a number of places there were round filling defects about $2 \mathrm{~mm}$ in diameter, consistent with a diagnosis of lymphangiectasia. A lymphangiogram showed hypoplastic lymphatics in the left leg; the right leg appeared normal but there a paucity of vessels passing through the right iliac region. There was an increase in the cross-circulating pattern across the lumbar vertebrae with poor opacification of the glands in the right external iliac chain, but normal filling of the para-aortic nodes and pre-aortic nodes. A laparotomy, done in 1978 , found chylous ascites and abnormal small bowel, particularly in the jejunum, with dilated lacteals on the surface of the intestine. A biopsy showed mostly normal villi but some with dilated lacteals. Secondary intestinal lymphangiectasia was excluded by appropriate investigations.

In September 1976 the patient, a heavy smoker, experienced sudden onset of pain in the right hand. A clinical diagnosis of radial artery occlusion was made. A right subclavian artery bruit was noted. The ESR was $40 \mathrm{~mm} / \mathrm{h}$. The platelet count was normal. Urinalysis was normal. Tests for antinuclear 
factor and DNA binding were negative. Subsequent exploration of the forearm vessels revealed atheroma and thrombus in the brachial artery, complete occlusion of the radial artery and stenosis of the ulnar artery. After thrombo-endarterectomy a brachio-ulnar artery saphenous vein bypass graft was undertaken. In 1978 the patient experienced a transient ischaemic attack affecting the territory of the left middle cerebral artery. Bilateral carotid bruits were noted. The ESR was $5 \mathrm{~mm} / \mathrm{h}$ and the platelet count was normal. Lipid profile was normal and repeated tests for auto-antibodies were negative. An arch aortogram revealed relatively normal origins and bifurcations of the common carotid arteries but the right vertebral artery appeared narrowed throughout its length. After two more transient ischaemic attacks, the patient was anticoagulated with warfarin and one month later he developed cardiac tamponade because of a haemorrhagic pericardial effusion. The warfarin was stopped. Cardiac catheterisation showed no evidence of significant pericardial or cardiac disease. Six months later the patient was found to be hypertensive and a renal arteriogram revealed complete obstruction of the right renal artery; the splenic artery was normal. The platelet count was $833 \times 10^{9} /$. Bone marrow examination showed normoblastic erythropoiesis and normal myelopoiesis. Megakaryocytes were slightly increased in numbers and showed active platelet budding.

Current treatment includes: a low fat diet, diuretics, $\beta$-blockers, aspirin and dipyridamole, and dietary supplements including vitamins, Triosorbon and MCT oil. His clinical condition has improved and is now stable.

\section{ASSESSMENT OF SPLENIC FUNCTION}

Peripheral blood films were scrutinised for the presence of target cells, giant platelets, acanthocytes and Howell-Jolly bodies. Pitted erythrocytes were counted by the method of Pearson et al: ${ }^{4}$ in our hands, the upper limit of normal is $4 \%$. Clearance studies were carried out by the method of Dacie and Lewis. ${ }^{5}$ Briefly, autologous erythrocytes were labelled with $1.4 \mu \mathrm{Ci}$ sodium ${ }^{99} \mathrm{Tc}$-pertechnetate and damaged by heating for $20 \mathrm{~min}$ at $50^{\circ} \mathrm{C}$. After re-injection of the cells, blood samples were taken at three and 20 minutes. The radioactivity remaining in the blood at 20 minutes, expressed as a percentage of the amount of radioactivity present at three minutes, was taken as a measure of heat-damaged red cell clearnace. Our normal range is 17.5 to $46.5 \%$. Splenic volume was computed from scintiscans obtained after injection of radio-labelled sulphur colloid. Our normal range of computed splenic volume being 158 to $577 \mathrm{ml}$.

\section{Results}

The serum albumin, absolute lymphocyte count, platelet count and pitted cell count in relation to the clinical course, are illustrated in the Figure.

\section{ALBUMIN}

Serum concentrations have been $\leqslant 30 \mathrm{~g} / 1$ (normal $37-49 \mathrm{~g} / \mathrm{l})$ since presentation in 1975.

\section{LYMPHOCYTE COUNT}

The absolute number of lymphocytes has fluctuated, falling to concentrations of $<1000 / \mathrm{mm}^{3}$ during 1980 when the patient was very ill. The proportion of T-lymphocytes has tended to be low: $51.5 \%$ in 1976 and $50 \%$ in 1982 (as detected by rosetting techniques and monoclonal antibody respectively).

\section{PLATELETS}

At presentation the platelet count and bone marrow examination were normal. The 1979 the platelet count rose to $675 \times 10^{9} / 1$, reaching a maximum of
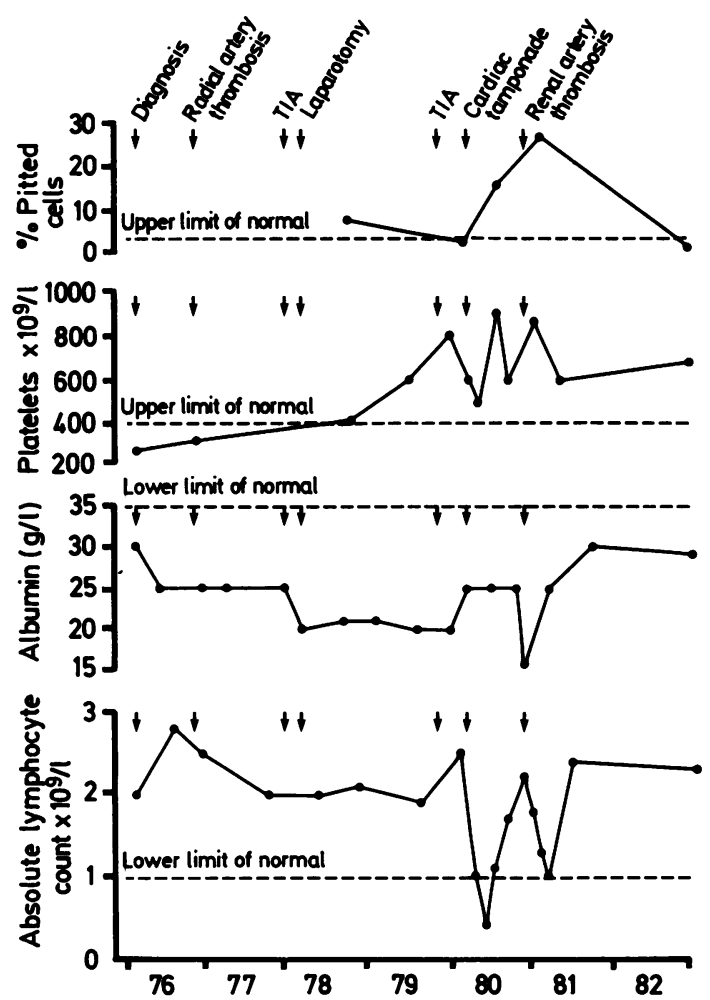

Figure Lymphocyte count, serum albumin, platelet count and pitted-cell count in relation to the clinical events during 1976-82. 
$979 \times 10^{9} / 1$ in 1980 and has remained above $500 \times$ $10^{9} / 1$. Bone marrow examination in 1980 revealed megakaryocyte hyperplasia.

\section{SPLENIC FUNCTION}

This was assessed by a peripheral blood film, heat damaged red cell clearance and splenic volume $(266 \mathrm{ml})$, and was normal at presentation. The first indication of impaired splenic function was the appearance of occasional acanthocytes in 1977. Three years later the peripheral blood film showed the typical features of hyposplenism: Howell-Jolly bodies, acanthocytes, target cells, and giant platelets, which persisted for at least 12 months. The pitted red cell count rose to a maximum of $29 \%$ in 1981 and a repeat scan of the spleen showed a decrease in volume $(116 \mathrm{ml})$. Follow up blood film and pitted cell count in December 1982 showed a return to normal. Unfortunately, we have not been able to repeat heat damaged red cell clearance.

\section{Discussion}

The abnormal concentrations of albumin and immunoglobulins found in our patient were typical of intestinal lymphangiectasia: IgG showed the greatest reduction, IgM was also low and IgA levels were normal. The lymphocyte count has been very low on only one occasion, when the patient had cardiac tamponade. The relatively normal lymphocyte count was unexpected in a patient with intestinal lymphangiectasia, however similar counts in the peripheral blood have been observed in some patients with intestinal lymphangiectasia. ${ }^{6}$ Lymphocyte loss into the gut, if severe or chronic, depresses the blood lymphocyte count but it has been shown in animals that blood lymphocyte count can be maintained in the face of lymphocyte loss, although there is a fall in T-lymphocyte numbers. ${ }^{7}$ Wieden $e t ~ a l^{8}$ have suggested that there is a change in lymphocyte subpopulations as a result of lymphocyte loss in intestinal lymphangiectasia, with a reduction in the numbers of long lived recirculating cells in the peripheral blood. Our finding of low number of T-cells in the peripheral blood is in keeping with this.

Soon after the diagnosis of intestinal lymphangiectasia was made, we began to study this patient's splenic function. In 1976, a peripheral blood film, heat damaged red cell clearance and splenic volume were normal. From 1978 to 1980 the blood films became progressively more abnormal until by 1980 there were target cells, giant platelets, acanthocytes and Howell-Jolly bodies present, features characteristic of hyposplenism. There was also an increase in the pitted red cell count which has been shown to correlate well with other estimates of splenic hypofunction. ${ }^{9}$ A repeat estimation of splenic volume showed a substantial decrease in size in 1981. Over the last two years, with an improvement in the patient's clinical condition, the blood film changes have regressed and the pitted red cell count has returned to normal.

Reversibility of abnormalities of splenic function in association with improvement in the clinical condition has been described in other conditions, including coeliac disease ${ }^{10}$ and inflammatory bowel disease. ${ }^{11}$ Provided that splenic hypofunction has not progressed to fibrosis and atrophy, it seems reasonable to postulate that if the pathological mechanism causing the hypo-function improves, splenic function might also improve.

Fish et al,${ }^{12}$ showed that after discontinuing lymph drainage in experimental animals, the spleen repopulated with lymphocytes. Two of the patients with intestinal lymphangiectasia described by Roberts and Douglas ${ }^{6}$ showed an increase in the peripheral blood lymphocyte count, presumably because of a reduction in the gastrointestinal loss of lymphocytes after treatment. As our patient's clinical state improved, there was a rise in the peripheral blood lymphocyte count and the hyposplenism resolved.

Impaired splenic function has also been shown to improve with remission in rheumatoid arthritis, possibly related to a fall in levels of circulating immune complexes. ${ }^{13}$ The possibility that our patient's transient hyposplenism was because of deposition and clearance of immune complexes seems unlikely as this association has been reported only in 'inflammatory', auto-immune disorders, ${ }^{13} 14$ for which we found no evidence in this case.

To our knowledge, the association of splenic hypofunction and intestinal lymphangiectasia has not been described. Crosby ${ }^{15}$ mentioned a personal observation of splenic atrophy in a patient with lymphoma and obstruction of intestinal lacetals. Ward $e t$ al $^{16}$ found a spleen of normal weight at necropsy in their patient with intestinal lymphangiectasia and commented on a marked reduction in the size of the lymphoid follicles. In view of the patient's preceding illness, however, including neoplasia and suppurative peritonitis, and his treatment, including blood transfusion and abdominal, radiation, it is difficult to interpret this finding.

The aetiology of the several vascular episodes in our patient is not clear but peripheral vascular disease, perhaps related to heavy smoking, and latterly the thrombocytosis, may be contributory. The persistent rise in the platelet count from 1978 is an interesting feature. Thrombocytosis is associated with anaemia ${ }^{17}$ but generally our patient was not 
anaemic. Thrombocytosis is associated with nonspecific inflammation of the bowel, as in inflammatory bowel disease ${ }^{18}$ and coeliac disease $;^{19}$ in our patient there was no evidence of inflammation of the bowel. Thrombocytosis is a well recognised consequence of hyposplenism ${ }^{20}$ although the role of the spleen in maintaining the normal platelet count is not well understood. Thrombocytosis may itself be a cause of impaired splenic function. Marsh et $a l^{21}$ found that some patients with essential thrombocythaemia also had splenic atrophy and Crosby ${ }^{15}$ postulated that splenic atrophy was a secondary effect due to infarction by clogging of the vessels with platelets in a way analagous to infarction caused by sickled red cells in sickle-cell disease. Platelet hyperactivity as a consequence of hyposplenism has been described in sickle-cell disease and in both sickle-cell disease and essential thrombocythaemia it has been suggested that the hyposplenism and thrombocytosis may interact to further increase the platelet count. ${ }^{21} 22$ This may have occurred in our patient and although the splenic artery was shown to be normal, clogging of small arteries within the spleen cannot be excluded.

Our reason for studying splenic function in this patient was the theoretical possibility that he might develop splenic hypofunction because of lymphocyte loss into the bowel. Although the prediction was borne out in this patient, however, other mechanisms may have been operating.

\section{References}

1 Schilling V. Uber die diagnose einer milzatrophie durch den befund von kernkugel als teilerscheinung pluriglandular insuffizienz. Klin Wochenschr 1924; 43: 1960-2.

2 Ryan FP, Smart RC, Holdsworth CD, Preston FE. Hyposplenism in inflammatory bowel disease. Gut 1978; 19: 50-5.

3 Bullen AW, Losowsky MS. Lymphocyte subpopulations in adult coeliac disease. Gut 1978; 19: 892-7.

4 Pearson HA, Johnston D, Smith KA, Touloukian RJ. The born-again spleen. Return of splenic function after splenectomy for trauma. N Engl J Med 1978; 298: 1389-92.

5 Dacie JV, Lewis SM. In: Practical haematology, London: Churchill Livingstone, 1975.

6 Roberts SH, Douglas AP. Intestinal lymphangiectasia: the variability of presentation. A study of five cases. $Q J$ Med 1976; 45: 39-48.

7 Strober W, Wochner RD, Carbonne PP, Waldemann TA. Intestinal lymphangiectasia: a protein losing enteropathy with hypogammaglobulinaemia, lymphopenia and impaired homograft rejection. J Clin Invest 1967; 46: 1643-56.

8 Weiden PL, Blaese RM, Strober W, Black JB, Waldemann TA. Impaired lymphocyte transformation in intestinal lymphangiectasia: evidence for at least two functionally distinct lymphocyte populations in man. J Clin Invest 1972; 51: 1319-25.

9 Corazza GR, Bullen AW, Hall R, Robinson PJ, Losowsky MS. Simple method of assessing splenic function in coeliac disease. Clin Sci 1981; 60: 109-113.

10 Palmer KR, Sherriff SB, Holdsworth CD. Changing pattern of splenic function in coeliac disease. [Abstract] Gut 1980; 20: A920.

11 Palmer KR, Sherriff SB, Holdsworth CD, Ryan FP. Further experience of hyposplenism in inflammatory bowel disease. $Q J$ Med 1981; 50: 463-71.

12 Fish JC, Beathard G, Sarles HE, Rimmer AR, Ritzmann JE. Circulating lymphocyte depletion: effect on lymphoid tissue. Surgery 1970; 67: 658-66.

13 Williams BD, Russell BA, Lockwood CM, Cotton C. Defective reticuloendothelial system function in rheumatoid arthritis. Lancet 1979; 1: 1311-4.

14 Lockwood CM, Worledge S, Nicholas A, Cotton C, Peters DK. Reversal of impaired splenic function in patients with nephritis or vasculitis (or both) by plasma exchange. $N$ Engl J Med 1979; 300: 524-30.

15 Crosby HC. Hyposplenism: an inquiry into normal function of the spleen. Ann Rev Med 1963; 14: 349-69.

16 Ward M, Le Roux A, Small UP, Sircus W. Malignant lymphoma and extensive viral wart formation in a patient with intestinal lymphangiectasia and lymphocyte depletion. Postgrad Med J 1977; 53: 753-7.

17 Selroos O. Thrombocytosis. Acta Med Scand 1973; 193: 431-6.

18 Morowitz DA. Allen LW, Kirsner JB. Thrombocytosis in chronic inflammatory bowel disease. Ann Intern Med 1968; 68: 1013-21.

19 Nelson EW, Estan A, Brooks FP, Cerda JJ. Thrombocytosis in patients with coeliac sprue. Gastroenterology 1976; 70: 1042-4.

20 Lipson RL, Bayrd ED, Watkins $\mathrm{CH}$. The postsplenectomy blood picture. Am J Clin Pathol 1959; 32: 526-32.

21 Marsh GW, Lewis SM, Szur L. The use of ${ }^{51} \mathrm{Cr}$-labelled heat damaged red cells to study splenic function. $\mathrm{Br} J$ Haematol 1966; 12: 167-71.

22 Kenny MW, George AJ, Stuart J. Platelet hyperactivity in sickle-cell disease: a consequence of hyposplenism. J Clin Pathol 1980; 33: 622-5. 